\title{
Levels and sources of stress in medical students
}

\author{
JENNY FIRTH
}

\begin{abstract}
Levels of stress, as measured by the general health questionnaire, were assessed in 318 medical students in their fourth year at three British universities. Mean scores were higher than those in other groups within the general population, and the estimated prevalence of emotional disturbance was $31 \cdot 2 \%$, a proportion similar to that reported in medical students in the United States. There were no differences in prevalence or in mean scores of stress between the sexes. Twelve (4\%) students reported high intake of alcohol, and almost half of the students had increased their intake in the past two years.

The four categories most commonly cited in answers to an open ended question on recent stressful events were talking to psychiatric patients, effects on personal life, presenting cases, and dealing with death and suffering. Relationships with consultants raised the strongest negative feelings, with 102 (34\%) students finding these particularly stressful.
\end{abstract}

Stress among medical students should be acknowledged and attempts made to alleviate it.

\section{Introduction}

Studies in the United States suggested that the practice of medicine entails certain risks to the mental health of both qualified physicians $\mathrm{s}^{1-3}$ and students, ${ }^{45}$ and links between the training and later problems of mental health have been suggested. ${ }^{6} \mathrm{~A}$ recent report, ${ }^{7}$ confirming earlier studies ${ }^{89}$ described particularly high levels of psychiatric distress in medical students in a university in the United States compared with the general population, with $15-20 \%$ of the students meeting criteria for a diagnosis of psychiatric

\footnotetext{
Medical Research Council/Economic and Social Research Council Social and Applied Psychology Unit, Department of Psychology, Sheffield University, Sheffield S10 2TN

JENNY FIRTH, BSC, MSC, research scientist
}

illness. Most studies report a higher prevalence in women than men. ${ }^{10}$ Undergraduate records from a British university, however, showed that only $2.4 \%$ of students developed a psychiatric disorder that led to absence from the course and $1 \%$ required admission to hospital for psychiatric disturbance. ${ }^{12}$ It was noted, however, that actual psychiatric morbidity was probably considerably higher.

This paper describes the first findings of a longitudinal study of stress in medical students and practitioners in the United Kingdom. I investigated the levels of stress experienced by medical students and considered whether these differed from those in certain other populations and between men and women. I also assessed alcohol intake by students, a factor implicated in mental health problems in doctors in later life. ${ }^{13}$ If medical students do have high levels of stress, it is necessary to know which parts of the training cause them, so that both the tasks and the student's ability to cope with them may be improved. ${ }^{14}$ The study, therefore, included qualitative data on sources of stress and satisfaction in medical training.

\section{Methods \\ THE QUESTIONNAIRE}

The questionnaire posed a variety of questions on personal history, stress, personality, and trait and asked for accounts of incidents that invoked stress. Those items that concern the present paper are:

The stress incident record ${ }^{15}$ - This contained an open ended question that required the student to: "Describe briefly a real event (other than examinations) which has occurred in the past month in your role as medical student, and which has been stressful to you (Note: A stressful event is one which has aroused your feelings in some negative way)" and to describe why this had been a problem. Students also rated the intensity of 15 feelings that they had experienced during the incident (such as powerlessness, guilt, tension, embarrassment) on a five point scale from "not at all" to "extremely." Mean scores were computed for each feeling and were used to establish the overall intensity of feelings related to each event.

Satisfactions-Students were asked to describe briefly what they liked most about their jobs. The answers to these open ended sections formed the basis of coding systems that were found to be adequately reliable (lowest $k=0.74){ }^{16}$

Stress-Students were asked to indicate particularly stressful items from a 
list of eight (see table III) that had previously been described as stressful by medical students in a pilot study.

The general health questionnaire ${ }^{17}$ - The 12 item version of this scale was designed as a screening device for estimating minor psychiatric disorders in the general population and is a useful measure of stress in occupational settings. ${ }^{18}$ Means were assessed using the Likert method, in which each item has a range of zero to three (maximum score 36 ), and prevalence estimations by using the method of the general health questionnaire, in which each item is scored zero to one (maximum score of 12).

Alcohol intake was assessed by asking students to rate their drinking habits on a five point scale: never, a little occasionally, a little often, a lot occasionally, a lot often. They were asked if their intake of alcohol had increased in the past two years. students and for a group of 222 young employed people (122 men and 100 women) recently studied in Britain. With a conservative cutting score of three/four and validity data from a previous study of young people ${ }^{20}$ the estimated prevalence of emotional disturbance was $31 \cdot 2 \%$ in medical students compared with $9 \cdot 7 \%$ found in the young unemployed people. ${ }^{21}$ Eleven $(4 \%)$ students scored 10 or more, compared with one young employed person.

Students scoring at or above the threshold of four on the general health questionnaire reported drinking significantly more than those scoring below four $(t=2 \cdot 13, \mathrm{p}<0 \cdot 05)$. Overall, $50(17 \%)$ of the 296 students who replied reported drinking "a lot occasionally" and $12(4 \%)$ " a lot often." Intake of alcohol had increased over the past two years for $141(48 \%)$ students. There were no significant differences $(t<1)$ between mean scores for male $(11 \cdot 56)$

TABLE I-Proportions of medical students and young employed people scoring at each value on general health questionnaire

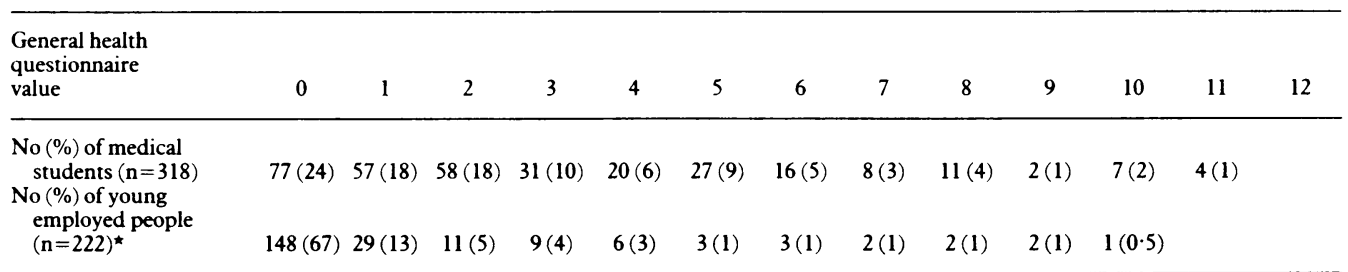

^Values provided from the Medical Research Council/Economic and Social Research Council Social and Applied Psychology Unit's study of youth unemployment (M Banks, P Ullah. The social and psychological effects of unemployment upon young people. Report submitted to Department of Employment 1985).

TABLE II-Events described as stressful by medical students

\begin{tabular}{|c|c|c|c|c|}
\hline \multirow[b]{2}{*}{ Event } & \multicolumn{2}{|c|}{ No (\%) reporting event } & \multirow[b]{2}{*}{ Total No (\%) } & \multirow[b]{2}{*}{ Mean level of feelings } \\
\hline & Men & Women & & \\
\hline No stressful event & $33(18)$ & $4(3)$ & $38(13)$ & \\
\hline Clinical tasks with patients & $5(3)$ & $6(5)$ & $11(4)$ & $2 \cdot 21$ \\
\hline Talking with patients & $32(18)$ & $27(23)$ & $61(20)$ & $2 \cdot 53$ \\
\hline Dealing with death or suffering & $18(10)$ & $13(11)$ & $31(10)$ & $2 \cdot 49$ \\
\hline Relationship with consultants & $9(5)$ & $6(5)$ & $15(5)$ & $2 \cdot 91$ \\
\hline Relationship with other doctors & $4(2)$ & $6(5)$ & $10(3)$ & $2 \cdot 58$ \\
\hline Academic work & $11(6)$ & $4(3)$ & $15(5)$ & $2 \cdot 58$ \\
\hline Effect on private life (relationships, finances, etc) & $25(14)$ & $10(9)$ & $36(12)$ & $2 \cdot 33$ \\
\hline \multirow{4}{*}{$\begin{array}{l}\text { Feeling that medical profession has failed } \\
\text { (embarrassing or distressing patients, possibility of } \\
\text { incompetence, etc) } \\
\text { Presenting cases, performing on ward rounds } \\
\text { Concerns over electives }\end{array}$} & & & & \\
\hline & $5(3)$ & $8(7)$ & $13(4)$ & $2 \cdot 73$ \\
\hline & $22(12)$ & $13(11)$ & $35(12)$ & $2 \cdot 38$ \\
\hline & $7(4)$ & $12(10)$ & $19(6)$ & $2 \cdot 64$ \\
\hline Total No who responded & 171 & 109 & 284 & \\
\hline
\end{tabular}

\section{SAMPLE AND PROCEDURE}

Medical students in their fourth year at the universities of Sheffield, Manchester, and Leeds were asked on the first day of their psychiatric placement to participate in the study. It was explained that the completion of the questionnaires was voluntary, that their answers were confidential, that the researcher had no connection with either the university faculty or the NHS, and that they would be sent $£ 2$ when completed questionnaires were returned in the stamped addressed envelopes provided.

Student's $t$ tests were used to compare mean scores for the sexes and analysis of variance to compare the universities. Differences between frequencies were analysed using $\chi^{2}$.

\section{Results}

Of the 405 questionnaires distributed to medical students, 318 were returned completed, giving a response rate of $79 \%$. Of the $318,186(59 \%)$ were from men.

The mean score on the general health questionnaire for the medical students was 11.66 (SD 5.16). This was considerably higher than scores reported in studies of working men $(8.98(4.08))$ and working school leavers $(8.67(5.07)),{ }^{18}$ and of young people in further education $(8.30(4.62))^{9}$ and below those of unemployed school leavers $(14 \cdot 06(6 \cdot 70)) .^{18}$

Using the scoring method of the general health questionnaire, Table I shows the proportions of subjects with each summed score for the medical
TABLE III-Numbers (\%) of medical students reporting categories of experience as "particularly stressful"

\begin{tabular}{lllr}
\hline \multicolumn{1}{c}{ Stressful experience } & Men & Women & Overall \\
\hline Relations with academic staff & $22(13)$ & $17(15)$ & $39(13)$ \\
Relations with consultants & $57(33)$ & $41(35)$ & $101(34)$ \\
Relations with ward staff & $17(10)$ & $15(13)$ & $32(11)$ \\
Physical examinations of patients & $21(12)$ & $11(9)$ & $32(11)$ \\
Talking with terminally ill patients & $38(22)$ & $29(25)$ & $69(24)$ \\
Too little responsibility & $46(27)$ & $33(28)$ & $81(28)$ \\
Too much responsibility & $35(21)$ & $34(29)$ & $73(25)$ \\
Effects on personal life & $49(29)$ & $40(34)$ & $92(31)$ \\
\hline Total No who responded & 171 & 117 & $294^{\star}$ \\
\hline
\end{tabular}

*Six responders did not give their sex.

and female students $(11 \cdot 71)$, and the number of women scoring four or more was not significantly greater $\left(\chi^{2}=0 \cdot 79\right)$. Differences in the scores existed between the three universities $(F=3.69, p<0.05)$, though no significant differences were found in the number of students scoring four or more at each university $\left(\chi^{2}=3.09\right)$.

Table II shows the types of events reported as stressful by male and female medical students. Four categories that were mentioned by fewer than 10 people were excluded-namely, relationships with ward staff (eight (3\%)); overwork (seven (2\%)); medical ethics (abortion, confidentiality, etc) (three $(1 \%)$ ); and uncodable categories (one). The four categories most 
commonly reported were talking with patients, effect on private life, presenting cases, and dealing with death and suffering. For the category talking with patients, 56 of the 61 incidents cited entailed conversations with psychiatric patients. A significantly larger proportion of men than women reported suffering no stressful event $\left(\chi^{2}=13.294, p<0.001\right)$. The categories of events that elicited the highest mean scores for feelings overall were relationships with consultants $(2 \cdot 91)$ and feeling that the medical profession had failed $(2 \cdot 73)$. The three most strongly reported feelings in response to events were frustration (mean score $3 \cdot 3)$, tension $(3 \cdot 1)$, and powerlessness $(3 \cdot 0)$.

Table III shows the proportions of students who reported the events in the list as "particularly stressful." Relationships with consultants were reported as most stressful by 101 (34\%) students, followed by effects on personal life (92 (31\%)).

Altogether 296 students responded to a question asking which parts of their training they liked best. One hundred and twenty (41\%) said talking to patients, $105(36 \%)$ feeling useful, $27(9 \%)$ solving a mystery by diagnosis, 14 $(5 \%)$ practical procedures, $11(4 \%)$ feeling part of a team, and eight $(3 \%)$ clinical specialties; $11(4 \%)$ did not answer.

\section{Discussion}

The findings show that relatively high mean levels of distress are experienced by both male and female medical students. They offer some confirmation of the recent American study that found the prevalence of psychiatric symptoms in medical students to be considerably higher than that in the general population.? More important than these overall mean scores is the finding that the experience of stress is more widespread among the students than among a group of young employed people (table I). Only $77(24 \%)$ students, compared with $148(68 \%)$ of the comparison group, were completely free of symptoms, and a considerable proportion of them scored at levels that suggest that they were at least at risk of psychiatric illness. The estimated prevalence of emotional disturbance in the students reflects earlier reports that $15-26 \%$ of students were in need of some kind of treatment. ${ }^{49}$

The general health questionnaire provides only a rough indication of morbidity, and any minor psychiatric distress indicated may well be short term. Differences between group scores may also reflect factors such as class and age rather than symptoms alone. Moreover, it is not surprising that students, faced with constant evaluation and a shortage of money and time, should suffer the symptoms of strain more than young employed people. Nevertheless, studies show that each year of medical training is stressful, with the fourth year no worse than others, and it is this prolongation of stress that is important. ${ }^{22}{ }^{23}$ Although other students face similar problems, they do so to a lesser extent and for fewer years. ${ }^{24} 25$

The high response rate of this study $(79 \%)$ compared with previous ones ${ }^{76}$ makes its findings of particular importance, especially as a recent epidemiological survey reported that nonresponders tended to be more depressed than responders. ${ }^{27}$ These results cannot, of course, be applied to all medical students, and the differences that were found in mean scores at the three universities indicate this. Nevertheless, the variation in these means was small, and, more importantly, there were no significant differences in estimations of prevalence, which partly negates the possibility that the students or courses were atypical. Indeed, the strain at a provincial university might well be less than that at London University, where financial and accommodation problems may be more pressing.

Intake of alcohol is difficult to measure accurately by questionnaire. Twelve students (4\%), however, scored at the top of the range, and $62(20 \%)$ were in the top two categories, with emotionally distressed students drinking most. Despite the American Medical Association's worry over students' intake of alcohol and later physician impairment, ${ }^{13}$ medical students do not seem to drink more than other students. ${ }^{28}$ Nevertheless, given that almost half of the sample had increased their intake during clinical years (when it might be expected to decrease owing to less leisure and greater maturity), the high proportion becomes more worrying.

Women students did not report higher levels of general stress than their male counterparts. Their scores showed no significant differences, and women did not represent a greater proportion of the group at risk than would be expected, given the larger number of male respondents as a whole. This finding supports that of Jenkins. ${ }^{29}$

Although there was no evidence to suggest that women students found different types of events more stressful than men, the most distinct difference elicited by the stress incident record was that a far greater proportion of men than women reported that no stressful event had occurred. Within a population of over 300 similar proportions of actual events would be expected to occur for both sexes, and, therefore, it seems that women either experience more stressful events or are more willing to admit to them. ${ }^{30}$ Alternatively, women may actually experience different treatment merely by working in an environment still largely populated, certainly at senior level, by men and so lacking female role models. ${ }^{31}{ }^{32}$ Whatever the reason, the difference is not reflected in reported symptoms.

Proportionately fewer women than men reported events that negatively affected their personal lives. This may be because most women have already faced some conflict between family and work when they take up a career with such long training. ${ }^{31}$

Contrary to American studies and to popular mythology, ${ }^{14} 24$ the students did not report overwork as a major source of stress. This may reflect cross cultural differences or may have been because of the wording of the open ended question, which sought acute rather than chronic stress. Even when the students were asked what they disliked most about their roles, however, overwork was not reported ${ }^{16}$; on the contrary, "feeling useless" was the commonest category.

Although talking to patients was the most reported category overall, this undoubtedly reflects the fact that all students were about to begin a psychiatry clerkship, and $90 \%$ of students who cited this category described an incident in which they had talked (or failed to talk) to a psychiatric patient. Any placement will produce its own particular stress, and this one may have been particularly liable to do so because the activity generally liked most by students was talking to patients. Perhaps it was the frustration of not being welcomed or helpful that made the psychiatric experience stressful for these students. The intensity of feelings expressed by some students in the open ended section of the stress incident record cannot be communicated by numbers alone, and excerpts from the actual accounts are reported elsewhere. ${ }^{33}$

Apart from talking to patients the classes of events most often described as stressful by students concerned the effect their medical training was having on their personal life, the anxieties invoked by being asked to take an active part in ward rounds (both of which may be unchangeable aspects of training), and dealing with death and suffering. The last category included reports of the difficulty of talking to someone who was dying, of coping with a relative's grief, and of being present at an unexpected death. Previous questionnaire studies have not reported this category as a concern to medical students, ${ }^{14} 24$ and it may be that open ended questions permit a lowering of defences against more stressful situations as compared with the direct questioning used in previous studies. ${ }^{1634}$

Teaching in British medical schools on matters concerning death may well be less than effective ${ }^{35}$ and my results show that it remains a potent source of distress to students. A move away from lectures towards tuition in small groups may be a more useful method of teaching such difficult subjects.

The category that most strongly aroused feelings was "relationship with consultants," students usually describing occasions when they had been humiliated before their fellows. This category was also reported as particularly stressful by the largest proportion of students (table III). "Feeling that the medical profession had failed" also often involved a senior doctor, and the strength of the students' feelings in these two categories seemed to reflect a concern that their mentors were less than perfect and that they might eventually repeat the pattern themselves. These problems should be remedied by the consultants concerned, with students being taught to handle their distress in this and other emotive situations.

Apart from tension and anxiety - not surprisingly associated with stress-the feelings of frustration and powerlessness were rated most strongly on the stress incident record. These feelings may be 
seen as an inevitable part of being a medical student but may also contribute to experiences of the "learned helplessness" described as being associated eventually with depression..$^{36} \mathrm{It}$ has been suggested that "the medical initiation rite" may well lead to learned helplessness and subsequent physician impairment."

There are undoubtedly many difficult, unchangeable aspects of medical training, but more emphasis on what students like-for example, talking to patients-might mediate these difficulties. Perhaps the mere acknowledgment of the usefulness of talking to patients would be one simple way to reduce feelings of frustration and powerlessness. Other methods suggested for reducing student stress are the use of small groups for teaching and support, ${ }^{35}$ sensitivity groups, ${ }^{37}$ and a counselling service. ${ }^{222 \times}$ The effect of giving workers control over certain aspects of their jobs has been reported as mediating the effects of high demands, ${ }^{39}$ and in medical education this has been partly achieved by the introduction of staffstudent committees that can examine for change the rules governing difficult aspects of jobs. ${ }^{* 1}$ At the very least staff need to be aware of stress levels, and any sense of this stress being an initiation rite should give way to a climate in which the difficulties faced by the different strata of the profession can be openly acknowledged.

I thank Professor Peter Warr, Dr Michael Banks, and Dr David Shapiro for their helpful comments on this paper, and the professors of psychiatry and staff at the universities of Sheffield, Leeds, and Manchester for their help in enabling this project to take place.

\section{References}

1 Vaillant G, Sobowale D, MacArthur C. Some psychological vulnerabilities of physicians. N Englf Med 1972;278:372-5.

2 Vincent MO. Some sequelae of stress in physicians. Psychiatr $\mathcal{f}$ Univ Ottawa 1983;8:120-4.

2 Vincent MO. Some sequelae of stress in physicians. Psychatr f Unw Ottawa 1983;8:120-4.
3 McCue JD. The effects of stress on physicians and their medical practice. N Engl f Med 1982;306:458-63.
19.

1982;306:458-63.
4 Pitts FN, Winokur, G, Stewart MA. Psychotic syndromes, anxiety symptoms, and response to itts FN, Winokur, G, Stewart MA. Psychotic syndromes, an
stress in medical students. Am $\mathcal{F}$ Psychiatry 1961;118:333-40.

5 Lloyd C, Gartrell NK. A further assessment of medical student stress. F Med Educ 1983;58:964-7. 6 Reibord SP. Psychological perspectives on iatrogenic physician impairment. Pharos 1983; Summer:2-8.

7 Lloyd C, Gartrell NK. Psychiatric symptoms in medical students. Compr Psychiatry 1984;25: $552-65$.

8 Hunter RCA, Prince RH, Schwartzman AE. Comments on emotional disturbances in a medical undergraduate population. JAMA 1961;83:989-92.

9 Saslow G. Psychiatric problems of medical students. F Med Educ 1956;31:27-33.

10 Lloyd C, Gartrell NK. Sex differences in student mental health. Am J Psychiatry 1981;138: $1346-51$.

11 Davidson V. Coping styles of women medical students. J Med Educ 1978;53:902-7.
12 Salmons PH. Psychiatric illness in medical students. Br f Psychiatry 1983;143:505-8.

13 AMA Council on Mental Health. The sick physician: impairment by psychiatric disorders, including alcoholism and drug dependence. FAMA 1973;223:684-7.

14 Huebner LA, Royer JA, Moore J. The assessment and remediation of dysfunctional stress in medical students. F Med Educ 1981;56:547-58.

15 Keenan A, Newton TJ. Stressful events, stressors and psychological strains in young professional engineers. Journal of Occupational Behaviour 1985;6:151-6.

16 Firth JA, Morrison L. What stresses health professionals? A coding system for their answers. $\mathrm{Br} \mathcal{F}$ Clin Psychol (in press).

17 Goldberg D. The detection of psychiatric illness by questionnaire. London: Oxford University Press, 1972 .

18 Banks MH, Clegg CW, Jackson PR, Kemp NJ, Stafford EM, Wall TD. The use of the general health questionnaire as an indicator of mental health in occupational settings. Joumal of Occupational Psychology 1980;53:187-94.

19 Banks MH, Jackson PR. Unemployment and risk of minor psychiatric disorder in young people: cross-sectional and longitudinal evidence. Psychol Med 1982;12:789-98.

20 Banks $\mathrm{MH}$. Validation of the general health questionnaire in a young community sample. Psychol Med 1983;13:349-53.

21 Goldberg DP. Manual of the general health questionnaire. NFER Publishing Company: Windsor, 1978 .

22 Alexander DA, Haldane JD. Medical education: a student perspective. Med Educ 1979;13. 336-41.

23 Adsett CA. Psychological health of medical students in relation to the medical education process. f Med Educ 1968;43:728-34.

24 Heins M, Fahey SN, Leiden LI. Perceived stress in medical, law and graduate students. 7 Med Educ 1984;59:169-79.

25 Bjorksten O, Sutherland S, Miller C, Stewart T. Identification of medical student problems and comparison with those of other students. F Med Educ 1983;58:759-67.

26 Mitchell RE, Matthews JR, Grandy TG, Lupo JV. The question of stress among first-year medical students. F Med Educ 1983;58:367-71.

27 Vernon SW, Roberts RE, Lees ES. Ethnic participation in longitudinal health studies. Am $\mathcal{f}$ Epidemiol 1984;119:99-113.

28 McAuliffe WE, Rohman M, Wechsler $\mathrm{H}$. Alcohol, substance use and other risk-factors of impairment in a sample of physicians-in-training. Advances in Alcohol and Substance Abuse 1984;4: 67-87.

29 Jenkins R. Sex differences in minor psychiatric morbidity. Psychol Med 1985;suppl 7.

30 Briscoe ME. Sex differences in perception of illness and expressed life satisfaction. Psychol Med 1978:8:339-45.

31 Murphy JM, Nadelson CC, Notman MT. Factors influencing first-year medical students' perceptions of stress. $\mathcal{F}$ Human Stress 1984;10:165-73.

32 Notman MT, Nadelson CC. Medicine: a career conflict for women. Am f Psychiatry 1973;130: 1123-7.

33 Firth JA. The stress of medical training. In Payne R, Firth J, eds: Stress in the health professions. Wiley: Chichester (in press).

34 Firth JA. Personal meanings of occupational stress: cases from the clinic. Fournal of Occupational Psychologv 1985;58:139-48.

35 Field D. Formal instruction in United Kingdom medical schools about death and dying. Med Educ 1984;18:429-34

36 Seligman MEP. Depression and learned helplessness. In RJ Friedman, MM Katz, eds. The psychology of depression: contemporary theory and research. Washington, DC: Winston and Sons, 1974.

37 Dashef SS, Espey WM, Lazarus, JA. Time-limited sensitivity groups for medical students. Am $\mathcal{J}$ Psychiatry 1974;31:287-92.

38 Spiro JH, Roenneburg M, Maly BJ. Teaching doctors to treat doctors: medical peer review. $\mathcal{F}$ Med Educ 1978;53:997-9.

39 Karasek RA. Job demands, job decisions, latitude and mental strain: implications for job redesign. Administrative Science Quarterly 1979;24:258-308.

40 Weinstein HM. A committee on well-being of medical students and house-staff. $\mathcal{J}$ Med Educ 1983;58:373-81.

(Accepled 27 January 1986)
Is antibiotic cover advised for patients with major joint prostheses who are undergoing surgical or dental procedures (such as scaling)?

The need for antimicrobial prophylaxis for patients with major joint prostheses has not been established. This question has been examined in the United States where an estimated 120000 hip or knee replacements were carried out in 1976 and in increasing numbers since then. Most haematogenous infections of prosthetic joints appear to have been secondary to acute or chronic foci of infection elsewhere in the body but, unexpectedly perhaps, not in relation to dental treatment. There appear to be only nine reported cases of infection of such joints attributed to dental bacteraemias but in none of these cases were the bacteria of a type likely to have originated from the mouth. Most infections were staphylococcal and none was caused by viridans streptococci (the main bacteria found in the blood after dental operations). This finding indicates that the regimens suggested for the prophylaxis of infective endocarditis in dental patients would be inappropriate for dental patients with joint replacements.

The variable nature of the bacteria causing secondary infections of prosthetic joints also makes it virtually impossible to make a rational choice of antibiotic. Moreover, the chance of such an infection is clearly statistically so remote that the risks from giving antibiotics are probably greater. In short, therefore, despite the natural anxieties of orthopaedic surgeons about this hazard, it must be said that, firstly, no cause and effect relation has been convincingly established between dental bacteraemias and secondary infection of prosthetic joints and, secondly, that, though such a possibility must exist-however remote it may be-the lack of any particular group of bacteria being predictably responsible would make a rational choice of antibiotic impossible. Blunderbuss use of several such drugs is likely to have a low benefit to risk ratio and does not seem advisable. - R A CAWson, professor of oral medicine and pathology, London.

Jaspers MT, Little JW. Prophylactic antibiotic coverage in patients with total arthroplasty: curren practice. FADA 1985;3:943-8

Little JW. The need for antibiotic coverage for dental treatment of patients with joint replacements Oral Surg 1983;55:20-3.

What treatment is advised for a 70 year old woman with urinary incontinence due to an unstable bladder?

An unstable bladder leaks when the intravesical pressure occasioned by an unstable detrusor contraction overcomes the resting urethral sphincter pressure. The principle of treatment for this condition is to try and "damp down" the unstable detrusor contractions to prevent leakage. In this patient it is not stated whether there is an associated pelvic floor weakness that should be assessed by a urethral pressure profile. The pelvic floor muscles may be strengthened by suitable exercises and the amplitude of the detrusor contractions reduced by various medications, mainly anticholinergic. A useful combination is propantheline $15 \mathrm{mg}$ thrice daily, together with imipramine $25 \mathrm{mg}$ thrice daily. If the incontinence cannot be controlled conservatively in this way by pharmacological means then various surgical procedures for the more resistant cases may be tried. These include endoscopic bladder transection ${ }^{1}$ or the use of bladder enhancement by "clam" cystoplasty. 2-J C GINGELL, consultant urologist, Bristol.

1 Parsons KF, Machin DG, Woofenden KA, Walmsley B, Abercrombie GF, Vinnicombe J. Endoscopic bladder transection. Br f Urol 1984;56:625-8.

2 Bramble FJ. The treatment of adult enuresis and urge incontinence by enterocystoplasty. $\mathrm{Br} \mathcal{f} \mathrm{Urol}$ 1982;54:693-6. 